\title{
Mapping African Animal Trypanosomosis risk from the sky
}

\author{
Jérémy BOUYER ${ }^{\mathrm{a}, \mathrm{b} *}$, Laure GUERRINI ${ }^{\mathrm{a}, \mathrm{b}}$, Marc DESQUESNES $^{\mathrm{a}}$, \\ Stéphane de la RocQUE ${ }^{a}$, Dominique CUISANCE ${ }^{\mathrm{c}}$ \\ ${ }^{a}$ Centre de coopération internationale en recherche agronomique pour le développement, \\ Département élevage et médecine vétérinaire, Montpellier, France \\ ${ }^{\mathrm{b}}$ Centre international de recherche-développement sur l'élevage en zone subhumide, \\ Bobo-Dioulasso, Burkina Faso \\ ${ }^{\mathrm{c}}$ Conseil général vétérinaire, 25 rue de Vaugirard, 75732 Paris Cedex 15, France
}

(Received 27 September 2005; accepted 28 February 2006)

\begin{abstract}
In Burkina Faso, African Animal Trypanosomosis (AAT) is still a major hindrance to cattle breeding, especially in the Mouhoun river basin, which was identified as a priority area for tsetse control. The attempt of the present work was to assess the abundance of tsetse flies and AAT risk using remote sensing coupled to field environmental data, along a Mouhoun river section of $234 \mathrm{~km}$ long, harbouring an open riverine forest where G. tachinoides Westwood is the predominant tsetse species. The water course was classified into three epidemiological landscapes, corresponding to a "disturbed", "natural" and finally "border" vegetal formation at the interface of the two formers. Using the mean number of infected flies by trap and by day as a risk indicator, the border landscape was found to be $5.4(1.3-12.0)$ and $15.8(4.7-41.6)$ times more risky than the natural and disturbed ones respectively. These results led to propose that a campaign against tsetse, undertaken by a development project called PAEOB (Projet d'Appui à l'Élevage dans l'Ouest du Burkina Faso), should be focussed on only $34 \%$ of the hydrographic network.
\end{abstract}

tsetse / African Animal Trypanosomosis / risk assessment / remote sensing

\section{INTRODUCTION}

In most sub-Saharan West-African countries infected by tsetse flies, African Animal Trypanosomosis (AAT) is considered to be one of the main pathological constraints to cattle breeding $[26,28,39,40]$. Tsetse flies are also cyclic vectors of sleeping sickness in humans. In line with the willingness of most African countries to solve the problem, a set of criteria/guidelines for joint inter-

*Corresponding author: bouyer@cirad.fr national action against tsetse-transmitted trypanosomosis was recently developed based on the concept of area-wide integrated pest management ${ }^{1}$ [24]. Priority areas for control were defined through entomological and epidemiological studies, which revealed variable situations and the need for diverse and integrated intervention tools.

\footnotetext{
${ }^{1}$ Vreyssen M., Robinson A.S., Hendrich J. (Eds.), Area-wide control of insect pests: from research to field implementation, Springer, Dordrecht, The Netherlands (in press).
} 
The prediction of the presence or abundance of tsetse flies using remote sensing coupled to field environmental data has become a priority. Based on statistical procedures and GIS (Geographical Information Systems) simulations, it has led to the development of very useful decision making tools at various levels (from local to regional) [16, 22, 36-38], confirming the potential of this approach. While an increase in agricultural activity is generally associated to a decrease in savanna tsetse species densities, the response of riverine tsetse species to human-driven changes is more varied. In West Africa, the presence of suitable riverine vegetation may be the main factor determining their presence and abundance $[5,14,15,34]$.

The Mouhoun river basin, in Burkina Faso, was identified as a priority area for tsetse control ${ }^{2}$ because of the high potential impact of trypanosomosis on cattle breeding and the vulnerability of riverine tsetse populations in this area, which has mosaic landscapes with topographic and agro-climatic divisions [24]. A recent study of the riverine vegetation permitted the division of the river into three major ecological sections: the tributaries, harbouring mainly a Guinean gallery forest, the western branch, harbouring a SudanoGuinean gallery forest, and the eastern branch, harbouring a Sudanese gallery forest [5]. Two riverine tsetse species, Glossina palpalis gambiensis Vanderplank 1949 (Diptera, Glossinidae) and G. tachinoides Westwood 1850, are still present in quite high densities and continue to transmit African trypanosomosis, however, G. morsitans submorsitans Newstead 1910 was not captured, although it was present

\footnotetext{
${ }^{2}$ IAEA/FAO, Workshop on strategic planning of area-wide tsetse and trypanosomiasis control in West Africa, IAEA, Ouagadougou, Burkina Faso, 2001.
}

in the area twenty years ago ${ }^{3}$. This disappearance may be multifactorial (increase in human density, decrease in wild fauna densities and disturbance of Savannah Woodlands). The type of riverine vegetation determined the dominant species; G. palpalis gambiensis was dominant in closed formations while $G$. tachinoides was dominant in the open galleries.

The aim of the present work was to assess tsetse fly densities and trypanosomosis risk levels in the various peri-riverine landscapes of the eastern branch of the Mouhoun using remote sensing data. This river section was first studied because of the greater dominance of $G$. tachinoides over G. palpalis gambiensis, which simplifies the understanding of tsetse distribution factors.

\section{MATERIALS AND METHODS}

\subsection{Context and location of the study}

Recently, human-driven changes of peri-riverine landscapes (under cropping and cattle grazing), studied by remote sensing, were associated with a decrease in riverine tsetse fly densities and an increase in cattle density subjected to trypanosomosis risk in Burkina Faso $[15,16]$. In particular, crop densities in $600 \mathrm{~m}$ buffers around the river course and their proximity to the river, measured from SPOT images, could be positively correlated to the disturbance of the gallery forests, with a negative impact on tsetse densities. Crop densities were also positively correlated to cattle densities. The aim of the present study was to validate these remote sensing indicators and assess riverine tsetse fly densities and trypanosomosis risk at a basin scale. The study area is located in

\footnotetext{
${ }^{3}$ Cuisance D., Politzar H., Recherche de gîtes d'expérience : suite de la prospection sur la Volta noire, CIRDES, Bobo Dioulasso, 1975.
} 


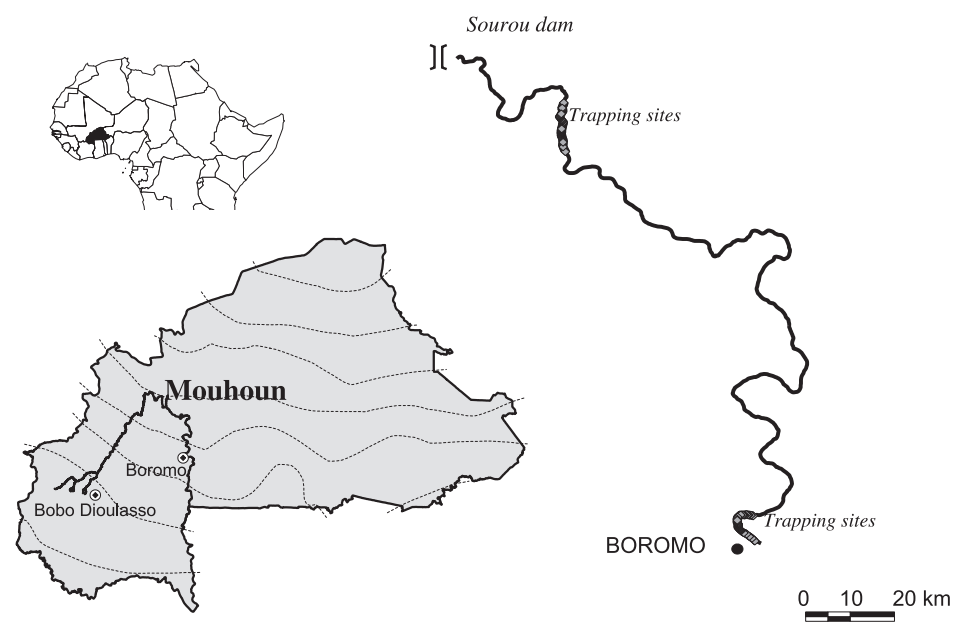

Figure 1. Location of the trapping sites on the eastern branch of the Mouhoun river, Burkina Faso.

the Mouhoun river basin, north of Bobo Dioulasso. In the present paper, the part of the Mouhoun river under study is called the eastern branch, extending from the Sourou dam $\left(3^{\circ} 26^{\prime} \mathrm{W}, 12^{\circ} 44^{\prime} \mathrm{N}\right)$ at the extreme north of the river to Boromo $\left(2^{\circ} 55^{\prime} \mathrm{W}\right.$, $\left.11^{\circ} 44^{\prime} \mathrm{N}\right)$, a town located between Bobo Dioulasso and Ouagadougou. It covers a total of $234 \mathrm{~km}$ of river course roughly oriented from the south to north (Fig. 1). In this section, where the Sudanese gallery forest occurs, G. tachinoides is the dominant tsetse species encountered and the disturbance level of the gallery has been negatively correlated to tsetse densities [5].

\subsection{Entomological and parasitological surveys}

Entomological surveys were conducted during the 2002 hot dry season (March for the eastern branch) [5]. Ten percent of the river course was sampled, using standardised biconic traps [7] 100-150 m apart, operated from $9.00 \mathrm{~h}$ to $16.30 \mathrm{~h}$. The 173 trap locations were recorded using GPS. Tsetse flies were recorded by species by trap (Apparent Density per Trap and per day or ADT) and sampled for dissection in the field. The proboscis, salivary glands, and mid-gut of part of the flies were directly examined using microscopes in the field. When at least one of these three organs in a fly was infected, all three were stored in distilled water kept at $-20{ }^{\circ} \mathrm{C}$ and analysed by PCR to determine the species of trypanosome involved with monospecific primers of Trypanosoma vivax, T. brucei sensu lato and $T$. congolense savannah type $[17,31]$. The proboscis of the other dissected flies were stored under the same conditions and analysed by PCR. In the following, only the mature infections, i.e. those of the proboscis, were considered to calculate the fly mature infection rates. In addition, the physiologic ages of some of the female $G$. tachinoides were determined by dissection of the ovary glands.

\subsection{Ecological surveys}

The riverine forest of each trapping site had been previously classed into three disturbance levels using phyto-sociological statements [5]. In addition, a semi-quantitative note of abundance 


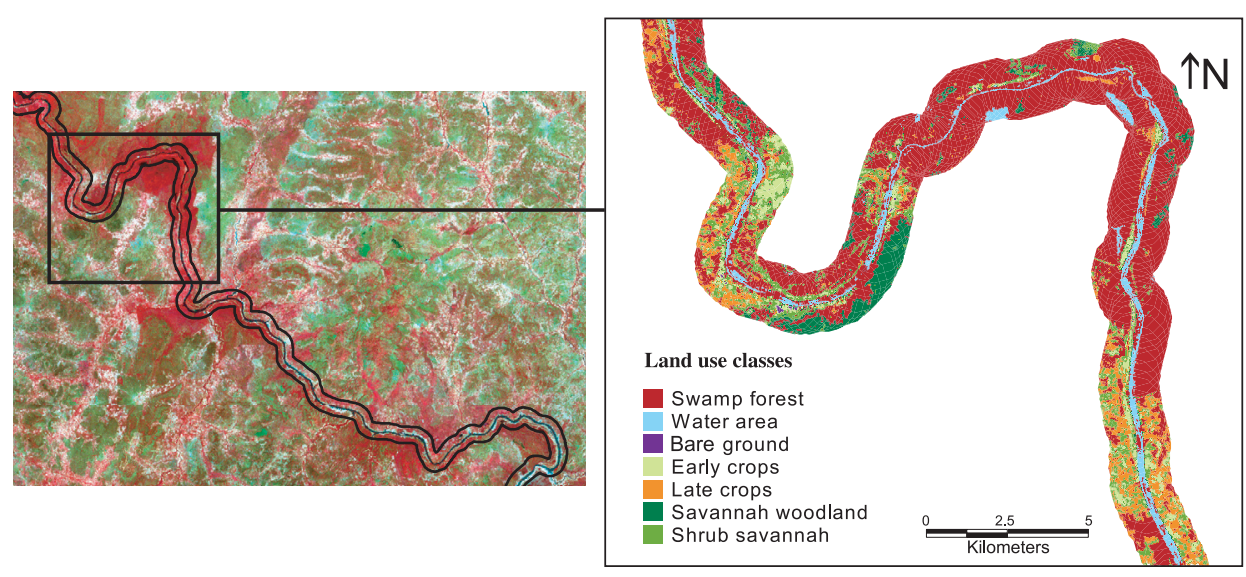

Figure 2. Three Landsat channel compositions (TM4, TM3, TM2) and associated supervised classification of a $1000 \mathrm{~m}$ buffer section, Mouhoun eastern branch, Burkina Faso.

(0, absence, 1, low, 2, medium, and 3, high) was attributed to each trapping site for domestic (small ruminants, pigs, and cattle) and natural hosts (reptiles and wild ruminants). The notes were attributed by using direct and footprint observations, and by interrogating a native guide.

During the entomological surveys, three entomological landscapes were identified in the field (protected forest, border of a protected forest, and cultivated and grazed areas) and were registered in all trap locations.

\subsection{Remote sensing treatments}

Two Landsat 7 thematic mapper (TM) images from October 1999 were needed to cover the eastern branch area. The river course was digitised from landsat images using Mapinfo 7.0 software. A buffer of $1 \mathrm{~km}$ width was extracted along the river course and submitted to a supervised classification (ENVI software) from a three channel composition (TM4, TM3, TM2), identifying seven land-use classes (Fig. 2). Standard nomenclature of African vegetation types was used to describe these land-use classes [4].

\subsection{Statistics}

The riverine forests are too small $(<10 \mathrm{~m})$ to be seen on a Landsat scene. Thus, the classification of the river course relays on the analysis of the neighbouring pixels. Similar methods are used in soil studies [29].

The aim of the following landscape classification method was to discriminate clusters corresponding to the three entomological landscapes described above (forest, border and disturbed) using the seven vegetal units obtained from the supervised classification in the pixels neighbouring the river course. First, 920 points, each separated by about $300 \mathrm{~m}$, were randomly generated all along the length of the river (Mapinfo software) from which 116 could be classed into these three landscapes using field data (Fig. 3). Among these 116 sites, 28, separated from each other by more than $1 \mathrm{~km}$, were used as learning sites and the 88 remaining sites were used to validate the results.

The 920 random points were always analysed together to identify clusters of similar neighbouring (Fig. 4). The areas of each land-use unit were calculated in buffers of 200, 500 and $1000 \mathrm{~m}$ around 

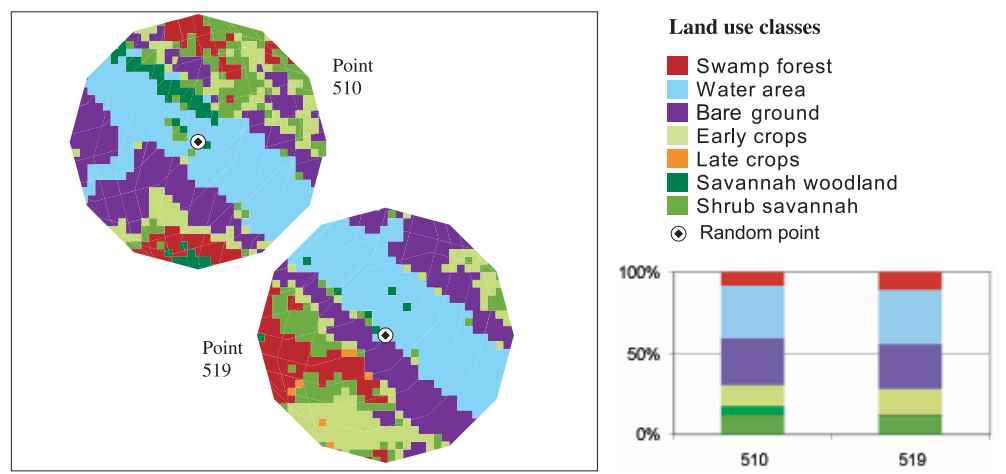

Figure 3. Percentages of seven vegetal units obtained from supervised classification in $500 \mathrm{~m}$ buffers around two points randomly generated along the river course.

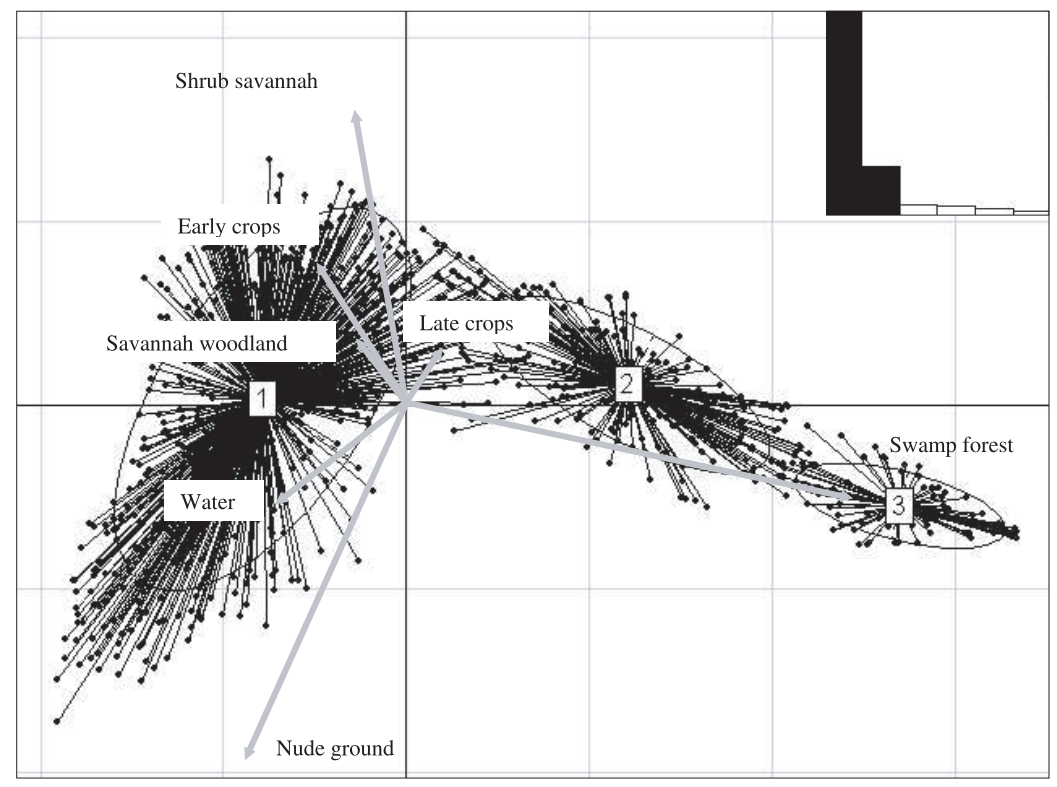

Figure 4. Projection of three distance groups and associated variables (Land use classes areas in $500 \mathrm{~m}$ buffers around the river course) on the first Principal Composant Analysis plan: Groups 1, 2, 3 represent disturbed, half-disturbed and natural landscapes respectively.

each point and they were reported to the total areas of the buffers to obtain the percentages of each vegetal unit (Fig. 3). Centred but not scaled principal composant analysis (PCA) was carried out using the land-use class areas in these buffers as variables for the three buffer sizes ( $\mathrm{R}$ software,
ADE4 package). Euclidian distances between the river points were calculated between all 920 river sites, either from the land-use class areas in the buffers or from their coordinates on the two principal axes. Hierarchical cluster analysis was then carried out with the complete 
Table I. Results of the Moran test applied on tsetse apparent densities with 11 neighbouring matrixes corresponding to various distance ranges.

\begin{tabular}{lcc}
\hline Distance range $(\mathrm{m})$ & Statistic & $p$-value \\
\hline $0-200$ & 0.4180 & 0.0010 \\
$200-400$ & 0.4297 & 0.0010 \\
$400-600$ & 0.3723 & 0.0010 \\
$600-800$ & 0.4542 & 0.0010 \\
$800-1000$ & 0.3958 & 0.0010 \\
$1000-1200$ & 0.3374 & 0.0010 \\
$1200-1400$ & 0.2251 & 0.0109 \\
$1400-1600$ & 0.1861 & 0.0259 \\
$1600-1800$ & 0.1304 & 0.0859 \\
$1800-2000$ & 0.0643 & 0.1868 \\
$2000-2200$ & -0.1115 & 0.8432 \\
\hline
\end{tabular}

agglomeration method [30] using the mva package ( $\mathrm{R}$ software).

The autocorrelation of tsetse fly densities between traps was investigated using the Moran I test under the assumption of randomisation $[2,3,9]$, applied on neighbouring matrixes, generated with $200 \mathrm{~m}$ distance ranges along the river course, from 0 to $2200 \mathrm{~m}$. The autocorrelation was then controlled with a permutation test for Moran I statistic, which makes no assumption on the distribution of the variable in the population [9]. The rows and columns of neighbouring matrixes correspond to the trap numbers. They are symmetrical and filled with " 1 " or " 0 " indicating if the trap in a column is a neighbour or not of the trap in a row within the selected distance range. The same pond was given to all the neighbours of a given trap to obtain row standardised spatial weight matrixes [8]. Eleven matrixes of neighbors (traps) were thus analysed (Tab. I) with the spdep package ( $\mathrm{R}$ software).

For each epidemiological landscape, the normality of tsetse apparent densities and physiologic age distributions was tested using the Kolmogorov-Smirnov test [10]. Since the distributions of apparent densities were not normal, they were compared altogether using a Kruskal-Wallis rank sum test [25] and then by pairs using the Steeltype non parametric multiple comparisons test (npmc package) [33]. Fly infection rates were compared using the Khi square test with Yates continuity correction [35]. The distributions of physiologic ages were normal and their means were thus compared with the Student $t$-Test with Welch modification to the degrees of freedom, after comparison of their variances with the F test. All the statistical analysis were computed with R statistical software [27].

The mean number of infectious flies by trap and by day is considered to be proportional to the vectorial capacity, a risk indicator of disease transmission corresponding to the number of infectious bites by time unit potentially produced by a single host threw the vector population [41]. The relative risks and their confidence intervals represented by the ratio of mean numbers of infectious flies by trap and by day were obtained from bootstrapping in the ADT distributions and from dissected fly samples from each landscape, assuming spatial homogeneity within a given epidemiological landscape (10 000 Monte Carlo simulations, @ risk software).

Confidence intervals were calculated for a risk $\alpha$ of 5\% [18].

\section{RESULTS}

\subsection{From remote sensing landscapes to epidemiological landscapes}

Seven land-use classes were identified in the peri-riverine buffers (Figs. 2 and 3). Swamp forests were dominated by Acacia seyal, Mitragyna inermis, and Mimosa pigra. Savannah woodlands were dominated by Butyrospermum paradoxum and Terminalia laxiflora. Shrub savannahs were 


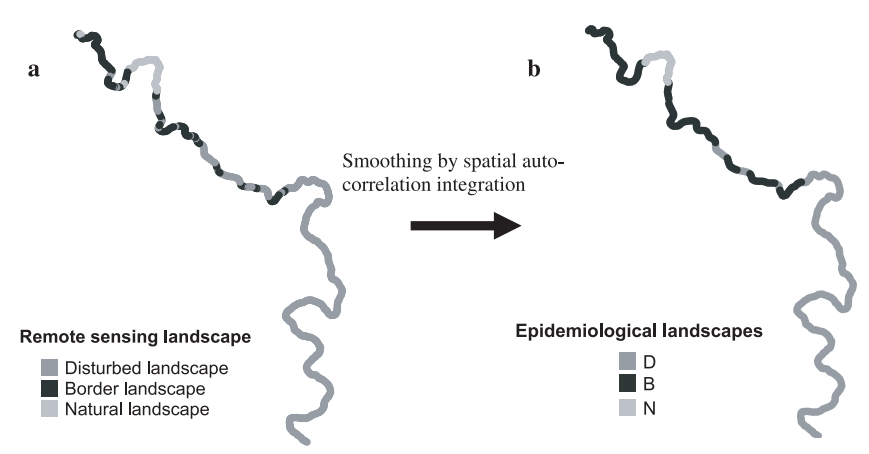

Figure 5. Distribution of remote sensing (a) and epidemiological (b) landscapes along the river course.

dominated by Combretum spp. and Guiera senegalensis. Two types of crops could be identified according to the timing of their implementation - early or late during the rainy season - both representing cereals (corn, millet, sorghum) or cotton crops. Bare ground comprised already harvested fields and eroded areas. The final class comprised water areas.

The hierarchical cluster analysis, applied either to the areas of the land-use classes in the $500 \mathrm{~m}$ buffers or to their coordinates on the two first principal axes of the PCA (same result), gave the best match between entomological and remote sensing landscapes (93\% of the 28 study sites). Among the 88 validation sites, there was a $90 \%$ match between entomological and remote sensing landscapes. The remote sensing landscapes were projected on the first plan of the PCA (Fig. 4), to qualitatively control their relationship to the variables (land use classes in the $500 \mathrm{~m}$ buffers). Among the 920 random locations along the river course, $87 \%$ of the variance was explained by the first two principal axes of the PCA. Swamp forest and bare ground units had the highest contribution to the first plan. These two variables were negatively correlated. The early crop unit was also negatively correlated to the swamp forest unit. The first remote sensing landscape (group 1, Fig. 4), called "disturbed”, corresponded to fully cultivated or grazed areas where protected forests were either nearly absent or not respected on both river banks. The second (group 2, Fig. 4), called "border landscape", was a mixed formation, corresponding to forest borders or respected protected areas on only one bank of the river. Finally, the third (group 3, Fig. 4), called "natural landscape", harboured mainly swamp forest and corresponded to respected protected areas on both river banks.

Fly densities were found to be autocorrelated up to the distance range of 1400 to $1600 \mathrm{~m}$ (Moran I test, Tab. I, $p<0.05)$. Thus, fly densities and infection rates between two adjacent remote sensing landscapes could not be considered independent. Natural and disturbed landscapes were always separated by halfdisturbed landscapes (Fig. 5a). To take auto-correlation into account and obtain independent epidemiological landscapes, this transition landscape was merged to $1600 \mathrm{~m}$ of adjacent natural and disturbed landscapes to create the first epidemiological landscape, coded B (for border). The residual natural landscapes constituted a second epidemiological landscape, coded N (for natural). Finally, the residual disturbed landscape formed a third epidemiological landscape, coded D (for disturbed). In the following discussion, only 

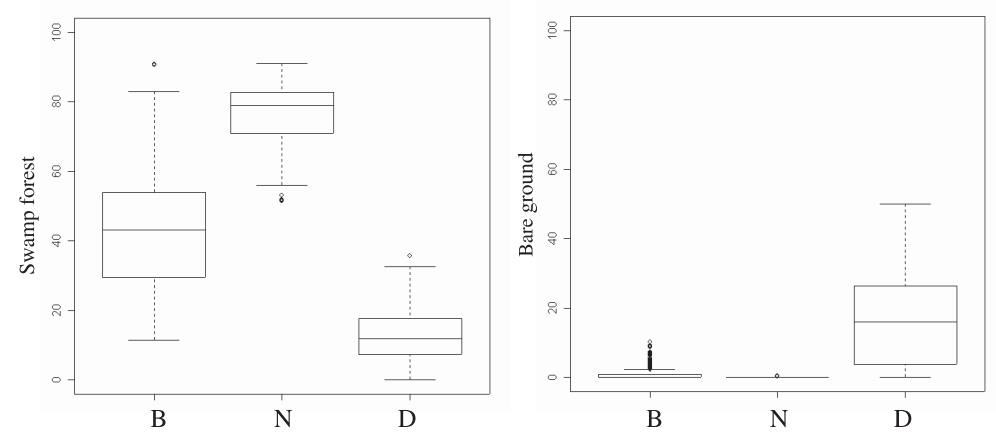

Figure 6. Boxplots of swamp forest and bare ground area percentages in the $500 \mathrm{~m}$ buffers around the river course, by epidemiological landscape.

these independent epidemiological landscapes are considered (Fig. 5b).

\subsection{Characterisation of the epidemiological landscapes}

Landscapes $\mathrm{B}, \mathrm{N}$, and $\mathrm{D}$ respectively represented 34,7 , and $59 \%$ of the total river length (Fig. 5b).

The swamp forest unit represented 43 (s.d. 17), 77 (s.d. 10), and 13 (s.d. 7) \% of the $500 \mathrm{~m}$ buffer surface in landscapes $\mathrm{B}, \mathrm{N}$, and D respectively (Fig. 6). The bare ground unit represented 1 (s.d. 2), 0 (s.d. 1), and 17 (s.d. 13) \% of the surface in landscapes $\mathrm{B}, \mathrm{N}$, and $\mathrm{D}$ respectively.

Fifty-six, 31, and 86 traps were located in landscapes $\mathrm{B}, \mathrm{N}$, and $\mathrm{D}$ respectively, where the riverine forest disturbance level was previously assessed from phytosociological analysis [5]. Landscape D harboured the most disturbed gallery, with $31 \%$ (s.d. $5 \%$ ) of degraded sites, followed by landscape B $(16 \%$, s.d. $5 \%)$ and finally landscape $\mathrm{N}(0 \%)$. The disturbance of the gallery forest was negatively correlated to the percentage of swamp forest surface in the $500 \mathrm{~m}$ buffers $\left(r^{2}=1\right)$.

Landscape D was the most frequented by cattle, with $75 \%$ (s.d. 6\%) of highly frequented sites, closely followed by landscape B (53\%, s.d. 5\%). Landscape N showed little cattle frequentation, accounting for only $10 \%$ (s.d. 5\%) of highly frequented sites. The percentage of sites highly frequented by cattle was negatively correlated to the swamp forest surface in the $500 \mathrm{~m}$ buffers $\left(r^{2}=0.98\right)$. The pattern of small ruminant frequencies was very similar. The frequency of pigs was very low, with only a low frequentation of two trapping sites in landscape $\mathrm{N}$, and absent from other landscapes. Reptiles (mainly Varanus niloticus and Crocodylus niloticus) and wild ruminants (mainly Tragelaphus scriptus and Cephalophus rufilatus) showed a frequentation pattern opposite to that of cattle.

\subsection{Epidemiological landscapes and risk assessment}

The apparent densities in the various landscapes were significantly different (Kruskal-Wallis Rank Sum Test, $\left.p<10^{-3}\right)$. The highest $G$. tachinoides mean apparent densities were observed in landscape B, with an ADT of 11.0 (s.d. 8.5), significantly higher than in landscapes $\mathrm{N}(p<0.05)$ and $\mathrm{D}$ (npmc test, Tab. II, $p<10^{-3}$ ) with ADT of 7.4 (s.d. 7.4) and 0.8 (s.d. 1.7) respectively (Tab. II). ADT of G. tachinoides in landscape $\mathrm{N}$ was also significantly higher than 
Table II. Comparison of the tsetse fly apparent densities in the epidemiological landscapes using the Steel-type non parametric multiple comparisons test (npmc package, R software).

\begin{tabular}{lcccc}
\hline Compared groups & Sum of both sample-sizes & Statistic & 1-sided $p$ value & 2-sided $p$ value \\
\hline D-N & 117 & 6.22 & $5.07 \mathrm{e}-10$ & $1.775073 \mathrm{e}-09$ \\
N-B & 87 & 2.46 & $2.00 \mathrm{e}-02$ & $3.87 \mathrm{e}-02$ \\
D-B & 142 & 9.75 & 0 & 0 \\
\hline
\end{tabular}

Table III. Tsetse fly mature infection rates by Trypanosoma vivax, T. congolense var. savannah and T. brucei lato sensu identified by PCR in the epidemiological landscapes.

\begin{tabular}{lccc}
\hline Trypanosome species & Landscape B & Landscape N & Landscape D \\
\hline T. vivax & 9 (s.d. 3) & 2 (s.d. 2) & 11 (s.d. 4) \\
T. congolense & 2 (s.d. 2) & 0 & 0 \\
T. brucei lato sensu & 1 (s.d. 1) & 0 & 0 \\
Sample size & 92 & 42 & 61 \\
\hline
\end{tabular}

in landscape D (npmc test, Tab. II, $p<$ $10^{-3}$ ). G. palpalis gambiensis was present in low densities in all landscapes, with ADT of 0.1 (s.d. 0.4) in landscapes B and $\mathrm{N}$ and of 0.01 (s.d. 0.1) in landscape D.

The physiological age of 17,4 , and 12 G. tachinoides were measured in landscapes B, N, and D respectively. The mean age was higher (Student $t$-Test, $p<0.05$ ) in landscape B (41 days old, s.d. 22) than in landscape D (29 days old, s.d. 12). The mean age in landscape $\mathrm{N}$ (47 days old, s.d. 22) could not be compared to other landscapes because of the low number of dissected flies.

The fly infection rates observed with the two methods (direct observation of 43 tsetse flies and PCR on 152 tsetse flies) were not significantly different (Khi square test, $p>0.05$ ) and their results were merged (Tab. III). T. congolense savannah type and $T$. brucei lato sensu were found only in landscape B, with low infection rates (Tab. III). T. vivax was found in a similar infection rate in landscape B and D, and in a lower infection rate in landscape $\mathrm{N}$ (not significant).

A risk indicator was obtained by multiplying fly apparent density distributions by fly mature infection rate distributions, all trypanosome species together. This product, representing a mean number of infectious flies by trap and by day was $1.2(0.6-1.9), 0.2(0-0.5)$, and $0.1(0-0.2)$ in landscapes $\mathrm{B}, \mathrm{N}$, and $\mathrm{D}$ respectively. In landscape $\mathrm{B}$, the trypanosomosis risk was thus 5.4 (1.3-12.0) and 15.8 (4.741.6) times higher than in landscapes $\mathrm{N}$ and $\mathrm{D}$ respectively $(p<0.05,1$ excluded from the $95 \%$ confidence intervals). No significant difference was observed between landscapes $\mathrm{N}$ and $\mathrm{D}(p>0.05,1$ included in the $95 \%$ confidence interval).

\section{DISCUSSION}

To distinguish entomological landscapes using remote sensing data, the use of $500 \mathrm{~m}$ buffers around the river course gave the clearest results. Human activities within this distance have the highest impact on riverine vegetation, as was shown in the same ecological area using $600 \mathrm{~m}$ buffers: the closer to the river the crops were, the greater the observed impact on riverine vegetation [15]. In the present study, the use of $1000 \mathrm{~m}$ buffers diluted the impact of erosion next to the 
river (represented by bare ground units) and failed to differentiate between riverine landscapes. However, $200 \mathrm{~m}$ buffers were no more precise, probably because the free water unit was contributing too much in the PCA axis. The $500 \mathrm{~m}$ buffers were optimal because the main contributing units to the PCA principal axis were swamp forests and bare grounds in the vicinity of the river. The complete agglomeration method finds similar clusters by using the maximal distance between all elements of the clusters to calculate the distance between clusters [1].

The study confirmed that peri-riverine human activities have a negative impact on gallery forest vegetation, in contrast to "protective" swamp forests. When small riverine forests (5 to $20 \mathrm{~m}$ width) are submitted to confusion and dilution, these "disturbance indicators" can be measured from remote sensing data like Landsat TM images, with a resolution of only $30 \mathrm{~m}$. These indicators can be related to riverine forest disturbance, and thus to a first epidemiological information layer: the vector densities. Recently, a similar approach in Ghana enabled the classification of the suitability of riverine habitats for G. tachinoides, although the relation was only qualitative [32]. The method used in the present study to predict tsetse densities is more explanatory than descriptive, differentiating itself from former works, led at a lower resolution $[22,36,38]$. Concerning a second epidemiological layer, the hosts, a negative correlation was observed between cattle frequency and swamp forest areas. It may be assumed that high cattle frequentation has a negative impact on this natural formation. Although the host density measures were only semi-quantitative, they were very easily obtained and were not time consuming. Moreover, more precise methods (particularly exhaustive cattle counting surveys) were used in the same ecological area, and similar results were found [15].
The $1.6 \mathrm{~km}$ observed autocorrelation between fly densities may be attributed to the dispersal capacities of riverine flies along the river course $[6,11]$. The decision to enlarge the border remote sensing landscape (half-disturbed) rather than the two others was made because the former is known to be particularly at risk since tsetse flies can find both breeding sites and domestic hosts there together [6]. This decision assumed that the majority of tsetse flies that become infected in the border landscape would be contained within this distance. In the same country and at the same season, the median distance (exceeded by $50 \%$ of the flies) measured for female $G$. tachinoides was $2.4 \mathrm{~km}$ [11]. However, this distance was measured in a homogeneous conserved Guinean gallery, which was not the case here, where a higher mortality rate (in disturbed places) and a heterogeneous distribution of host species could contribute to a reduction of the median distance. In fact, tsetse dispersion can be modelled as a killed random walk or diffusion process where life-span has a dramatic impact on the probability of long-distance movements ${ }^{4}$ [19-21].

Landscape $\mathrm{N}$ corresponded to protected areas on both banks of the river that are not supposed to be frequented by cattle. However, a low frequentation by cattle was recorded. The tsetse mature infection rate was low but their apparent density was high. Wild ruminants and reptiles were frequent in this landscape, although their density was lower than cattle in other landscapes due to intensive poaching in this area. Cattle breeders should be

\footnotetext{
${ }^{4}$ Bouyer J., Sibert A., Desquesnes M., Cuisance D., de La Rocque S., A model of diffusion of Glossina palpalis gambiensis (Diptera: Glossinidae) in Burkina Faso, in: Vreyssen M., Robinson A.S., Hendrich J. (Eds.), Areawide control of insect pests: from research to field implementation, Springer, Dordrecht, The Netherlands (in press).
} 
discouraged from using these river sections, which cannot be considered a priority for campaigns against tsetse.

Landscape D harboured a younger tsetse population than landscape B, in low apparent density, which could be attributed to a higher adult mortality rate, since the percentage of disturbed riverine forests is greater in this landscape. Cattle were present in high density. Fly mature infection rate by $T$. vivax was high, but trypanosomosis risk was low because of a low tsetse fly density.

Finally, landscape B harboured an intermediary disturbance level of the riverine forest, leaving many breeding places for a xerophylous species such as $G$. tachinoides $^{5}[6,13,34]$. The frequency of cattle was high, providing an abundant amount of preys. Vector density was higher than in the other two landscapes and the tsetse population was older than in landscape $\mathrm{D}$, which is another risk factor, since the mean incubation times of trypanosomes are about 10 , 14, and 30 days respectively for T. vivax, T. congolense and T. brucei brucei [12]. T. congolense and T. brucei lato sensu were found only in this landscape. Assuming that the mature infection of a fly had no implication on the probability of its capture, and that the mean apparent densities were positively correlated to the threat posed to cattle by tsetse thanks to the high number of traps in each landscape, the ratio of captured infected flies was considered a reflection of the risk level of the river sections studied. Using this risk indicator, landscape B is shown to be 15.8 times more risky than landscape $\mathrm{D}$ and should be a priority in a campaign against tsetse.

The border ecosystem, renowned for its impact on various invertebrate families,

\footnotetext{
${ }^{5}$ Gruvel J., Contribution à l'étude écologique de Glossina tachinoides Westwood 1850 (Diptera, Muscidae) dans la réserve de Kalamaloué, vallée du Bas-Chari, Thèse doctorale, Université de Paris VI, Paris, France, 1974.
}

also has a critical importance for African trypanosomosis epidemiology. In riverine ecosystems, it is correlated to humandriven changes of peri-riverine landscapes, which in turn can be studied by remote sensing. Remote sensing has already been used successfully to predict vector densities at low scales $[23,36-38]$. In the present study, it was used to stratify African animal trypanosomosis risk at a local scale, and it led to the proposition that a campaign against tsetse, which will be achieved by a development project, the PAEOB (Projet d'Appui à l'Élevage dans l'Ouest du Burkina Faso), should be focussed on only $34 \%$ of the hydrographic network. It also revealed that as far as tsetse flies are concerned, protecting only one river bank in this area is a dangerous conservation strategy for cattle. The methodology was derived from a previous work at a higher scale $[15,16]$, but proposes a simplified protocol for cattle density measurements and a rapid risk assessment that is compatible with the field constraints encountered within a river basin. Thanks to this rapid risk assessment method, a river section of $250 \mathrm{~km}$ could be analysed in this way within 3 months. The results were fully in line with a Trypanosomosis parasitological survey in cattle conducted in $1999^{6}$. The same work will take place in two other Mouhoun river sections with different ecological characteristics, the western part and the tributaries, where river forests are of the Sudano-Guinean and Guinean ecotypes respectively.

\footnotetext{
${ }^{6}$ Tamboura I., Bere A., Hendrickx G., Éléments d'élaboration d'un plan de contrôle de la trypanosomose dans les zones libérées de l'onchocercose. Les techniques de l'information spatiale et de l'épidémiologie : des outils utiles pour planifier un développement intégré de l'élevage en Afrique Occidentale, Bobo-Dioulasso, IMT Anvers, 2000.
} 


\section{ACKNOWLEDGEMENTS}

This work was carried out with the support of an FSP project (French foreign ministry) and of the Welcome Trust project No. 075824. Special thanks to the director general of CIRDES, Prof. Abdoulaye Gouro, for provision of excellent working conditions, to Félix Sanou, Willfried Yoni, Bila Cene, Adama Sana, Moïse Zoungrana and Boureima Sanou for their assistance during the field studies, and to François Roger and Sophie Thévenon for reading the manuscript.

\section{REFERENCES}

[1] Anderberg M.R., Cluster Analysis for Applications, Academic Press, New York, 1973

[2] Anselin L., Local indicators of spatial association, Geographical Analysis 27 (1995) 93-115.

[3] Anselin L., The Moran scatterplot as an ESDA tool to assess local instability in spatial association, in: Fiscjer M.M., Scholten H.J., Unwin D. (Eds.), Spatial analytical perspectives on GIS, Taylor and Francis, London, 1996, pp. 111-125.

[4] Aubreville A., Accord à Yangambi sur la nomenclature des types africains de végétation, Bois For. Trop. 51 (1957) 23-27.

[5] Bouyer J., Guerrini L., César J., de la Rocque S., Cuisance D., A phyto-sociological analysis of the distribution of riverine tsetse flies in Burkina Faso, Med. Vet. Entomol. 19 (2005) 372-378.

[6] Buxton P.A., The Natural History of Tsetse Flies. An Account of the Biology of the Genus Glossina (Diptera), Lewis H.K. and Co. Ltd, London, 1955.

[7] Challier A., Laveissière C., Un nouveau piège pour la capture des glossines (Glossina: Diptera, Muscidae) : description et essais sur le terrain, Cahier ORSTOM, série Entomologie médicale et Parasitologie 10 (1973) 251-262.

[8] Cliff A.D., Ord J.K., Spatial autocorrelation, Pion, London, 1973.

[9] Cliff A.D., Ord J.K., Spatial Processes: Models and Applications, Pion, London, 1981.
[10] Conover W.J., Practical Nonparametric Statistics, John Wiley and Sons, New York, 1971.

[11] Cuisance D., Février J., Dejardin J., Filledier J., Dispersion linéaire de Glossina palpalis gambiensis et $G$. tachinoides dans une galerie forestière en zone soudano-guinéenne (Burkina Faso), Rev. Elev. Med. Vet. Pays Trop. 38 (1985) 153-172.

[12] Cuisance D., Itard J., Desquesnes M., Frézil J.L., de La Rocque S., Trypanosomoses, épidémiologie, in: Lefèvre P.-C., Blancou J., Chermette R. (Eds.), Principales maladies infectieuses et parasitaires du bétail. Europe et Régions chaudes, Lavoisier, Londres - Paris - New York, éditions Tec et Doc/Éditions médicales internationales, 2003, pp. 1627 1650 .

[13] Davies H., Les Glossines dans le NordNigeria, Ibadan University Press, MaisonsAlfort, 1967.

[14] De La Rocque S., Augusseau X., Guillobez S., Michel V., De Wispelaere G., Bauer B., Cuisance D., The changing distribution of two riverine tsetse flies over 15 years in an area increasingly occupied by agriculture in Burkina Faso, Bull. Entomol. Res. 91 (2001) 157-166.

[15] De la Rocque S., Michel J.F., Cuisance D., De Wispeleare G., Solano P., Augusseau X., Arnaud M., Guillobez S., Du satellite au microsatellite. Le risque trypanosomien. Une approche globale pour une décision locale, Cirad, Montpellier, 2001.

[16] De La Rocque S., Michel J.F., Bouyer J., De Wispelaere G., Cuisance D., Geographical Information Systems in parasitology: a review of potential applications using the example of animal trypanosomosis in West Africa, Parassitologia 47 (2005) 97-104.

[17] Desquesnes M., Davila A.M.R., Applications of PCR-based tools for detection and identification of animal trypanosomes: a review and perspectives, Vet. Parasitol. 109 (2002) 213-231.

[18] Fowler J., Cohen L., Practical statistics for field biology, John Wiley and Sons Ltd, Chichester, 1990.

[19] Hargrove J.W., The effect of ambiant temperature on the flight performance of the mature male tsetse flies: Glossina morsitans, Physiol. Entomol. 5 (1980) 397-400.

[20] Hargrove J.W., Lange K., Tsetse dispersal viewed as a diffusion process, Transactions of the Zimbabwe Scientific Association 64 (1989) 1-8. 
[21] Hargrove J.W., A theoretical study of the invasion of cleared areas by tsetse flies (Diptera: Glossinidae), Bull. Entomol. Res. 90 (2000) 201-209.

[22] Hendrickx G., Napala A., Dao B., Batawui D., De Deken R., Vermeilen A., Slingenbergh J.H.W., A systematic approach to area-wide tsetse distribution and abundance maps, Bull. Entomol. Res. 89 (1999) 231-244.

[23] Hendrickx G., Napala A., Slingenbergh J.H.W., De Deken R., Vercruysse J., Rogers D.J., The spatial patterns of trypanosomosis predicted with the aid of satellite imagery, Parasitology 120 (2000) 121-134.

[24] Hendrickx G., de la Rocque S., Mattioli R.C., Long-term tse-tse and trypanosomiasis management options in West Africa, FAO, Rome, 2004.

[25] Hollander M., Wolfe D.A., Non parametric statistical inference, John Wiley and Sons, New York, 1973.

[26] Hursey B.S., Slingenbergh J., The tsetse fly and its effects on agriculture in subSaharian Africa, Rev. Mond. Zootech. 84 (1995) 67-73.

[27] Ihaka R., Gentleman R., R: A language for data analysis and graphics, J. Comput. Graph. Stat. 5 (1996) 299-314.

[28] Itard J., Cuisance D., Tacher G., Trypanosomoses: historique - répartition géographique, in: Lefèvre P.-C., Blancou J., Chermette R. (Eds.), Principales maladies infectieuses et parasitaires du bétail. Europe et Régions chaudes, Lavoisier, Londres - Paris - New York, Éditions Tec et Doc/Éditions médicales internationales, 2003, pp. 16071615.

[29] Lagacherie P., Robbez-Masson J.M., Nguyen-The N., Barthès J.P., Mapping of reference area representativity using a mathematical soilscape distance, Geoderma 101 (2001) 105-118.

[30] Lebart L., Morineau A., Piron M., Statistique exploratoire multidimensionnelle, Dunod, Paris, 1995.

[31] Lefrançois T., Solano P., de La Rocque S., Bengaly Z., Reifenberg J.M., Kabore I.,
Cuisance D., New epidemiological data on animal trypanosomosis by molecular analysis in the pastoral zone of Sidéradougou, Burkina Faso, Mol. Ecol. 7 (1998) 897-904.

[32] Mahama C.I., Kone A., de La Rocque S., De Deken R., Geerts S., Prediction of the distribution of Glossina tachinoides (Diptera: Glossinidae) in the Volta basin of northern Ghana, Bull. Entomol. Res. 95 (2005) 63-67.

[33] Munzel U., Hothorn L.A., A unified approach to simultaneous rank test procedures in the unbalanced one-way layout, Biom. J. 43 (2001) 553-569.

[34] Nash T.A.M., Tsetse Flies in British West Africa, His Majesty's stationery office, London, 1948.

[35] Patefield W.M., Algorithm AS159. An efficient method of generating $\mathrm{r} \times \mathrm{c}$ tables with given row and column totals, Appl. Stat. Medicine 30 (1981) 91-97.

[36] Robinson T., Rogers D., Brian W., Mapping tsetse habitat suitability in the common fly belt of Southern Africa using multivariate analysis of climate and remotely sensed vegetation data, Med. Vet. Entomol. 11 (1997) 235-245.

[37] Rogers D.J., Randolph S.E., Distribution of tsetse and ticks in Africa: past, present and future, Parasitol. Today 97 (1993) 226-271.

[38] Rogers D.J., Hay S.I., Packer M.J., Predicting the distribution of tsetse flies in West Africa using temporal Fourierprocessed meteorological-satellite data, Ann. Trop. Med. Parasitol. 90 (1996) 225-241.

[39] Shaw A.P.M., Economic guidelines for strategic planning of tsetse and trypanosomiasis control in West Africa, FAO, Rome, 2003.

[40] Swallow B., PAAT position paper: Impact of trypanosomosis on African agriculture, FAO-OMS-IAEA-OAU/IBAR, Rome, 1998.

[41] Tran A., Biteau-Coroller F., Guis H., Roger F., Modélisation des maladies vectorielles, Épidémiologie et santé animale 47 (2005) 35-51. 